\title{
MEDIO AMBIENTE Y ACCIONES POPULARES EN COLOMBIA: UN ESTUDIO EMPÍRICO*
}

\author{
COLLECTIVE LITIGATION OF \\ ENVIRONMENTAL RIGHTS IN \\ COLOMBIA: AN EMPIRICAL STUDY
}

\author{
Ángela María Páez-Murcia** \\ Everaldo Lamprea-Montealegre $e^{* * *}$ \\ Catalina Vallejo-Piedrahíta ${ }^{* * * *}$
}

Fecha de recepción: 22 de julio de 2016 Fecha de aceptación: 26 de enero de 2017 Disponible en linea: 30 de mayo de 2017

\section{Para citar este artículo/To cite this article}

\begin{abstract}
Páez-Murcia, Ángela María; Lamprea-Montealegre, Everaldo \& VallejoPiedrahíta, Catalina, Medio ambiente y acciones populares en Colombia: un estudio empírico, 134 Vniversitas, 209-248 (2017). http://dx.doi. org/10.11144/Javeriana.vj134.maap
\end{abstract}

doi:10.11144/Javeriana.vj134.maap

* Esta investigación fue financiada por la Facultad de Derecho de la Universidad de Los Andes. Agradecemos las contribuciones de quienes apoyaron este estudio. A la Universidad de La Sabana, por facilitar la participación de la profesora Ángela Páez. A la profesora Deborah Hensler por sus cuidadosos comentarios en la etapa del diseño de la metodología del estudio. A Andrea Padilla por su valioso aporte a la codificación de las sentencias y a Johnattan García por su apoyo en la construcción y optimización de la base de datos.

** Abogada y magíster en derecho administrativo, Universidad del Rosario. PhD en administración pública, Universidad de Kansas. Profesora, Facultad de Derecho y Ciencias Políticas, Universidad de La Sabana, Bogotá, Colombia. Contacto: angela.paez@unisabana.edu.co

*** JSD Stanford Law School. Abogado, Universidad de Los Andes. Profesor Asociado, Facultad de Derecho, director del área de derecho administrativo y director de la Clínica de Medio Ambiente y Salud Pública, MASP, Universidad de Los Andes. Contacto: e-lampre@uniandes.edu.co

**** Abogada, Universidad Autónoma Latinoamericana. Especialista en derecho administrativo, Universidad de Antioquia. Magíster en estudios de paz, Universidad de Innsbruck. Candidata al doctorado en derecho, Universidad de Los Andes, Bogotá, Colombia. Investigadora afiliada al Centre on Law \& Social Transformation (Bergen, Noruega). Contacto: c.vallejo13@uniandes.edu.co 


\section{RESUMEN}

Este artículo presenta los resultados de un estudio empírico que sistematizó las acciones populares falladas por el Consejo de Estado colombiano durante un período de 17 años (1998-2015). Los autores utilizaron metodologías de análisis cuantitativo y cualitativo para sistematizar más de 250 fallos de acciones populares decididas por el Consejo de Estado. Los resultados presentados en este artículo muestran las tendencias más importantes del litigio de acciones populares ambientales en Colombia: tipos de demandantes y demandados; tipo de recursos medioambientales protegidos; tasas de éxito de los demandantes; regiones y ciudades más litigiosas; efectos generales del incentivo económico en el tipo de litigio, entre otras variables. Los resultados de este estudio también muestran que el incentivo económico para las acciones populares no estaba favoreciendo los intereses de litigantes temerarios, como lo sostuvo el gobierno nacional cuando propuso al Congreso una reforma a las acciones populares, que se concretó en la Ley 1425 de 2010. Finalmente, se sugiere que la eliminación del incentivo económico de las acciones populares puede tener un efecto negativo sobre el litigio de interés público.

Palabras clave: Acciones populares; medio ambiente; Consejo de Estado; incentivo económico 


\section{ABSTRACT}

This paper presents the results of an empirical study that systematized environmental judicial opinions handed down by Colombia's highest administrative Court - Consejo de Estado- over a 17-year period (1998-2015). Thanks to a research grant, the authors and a team of coders systematized, using state-of-the art content analysis methodologies, more than 250 opinions handed down by Colombia's highest administrative Court. The results presented in this paper show the most important trends of collective environmental litigation in Colombia: types of plaintiffs and defendants; type of environmental resources involved in the case; plaintiffs' success rates; most litigious regions and cities; overall effects of economic incentives on the type of litigation, among several other subjects. This paper concludes that collective environmental litigation has been instrumental to protect environmental resources in Colombia, one the most biodiverse countries in the world. Finally, the paper concludes that the elimination in 2011 of the economic incentive in favor of litigants did not favor public interest litigation.

Keywords: class actions; environmental litigation; highest administrative court (Consejo de Estado); economic incentive

\section{SUMARIO}

Introducción.- I. Metodología.- II. Resultados.- $A$. Año de inicio del proceso y de decisión del caso.- B. Incentivo económico y costas.- $C$. Constitucionalidad de la ley derogatoria del incentivo económico.- D. Las partes procesales: demandantes y demandados. - E. Litigantes recurrentes e incentivo económico.- $F$. Temática del litigio: derechos o recursos afectados por el daño ambiental.- G. Tasa de éxito de los demandantes.- H. Secciones de decisión y consejeros ponentes.- CONCLUSIONES.- BibLIOGRAFía. 


\section{INTRODUCCIÓN}

El litigio colectivo asume una diversidad de formas alrededor del mundo ${ }^{1}$. Las acciones de clase estadounidenses (class actions) son el ejemplo más conocido de un tipo de litigio que se origina por el daño causado a un grupo de personas con intereses compartidos — pueden ser un puñado o miles de individuos_-, que es apoderado por un litigante que se constituye en el representante de la clase. En los class actions estadounidenses, la mayoría o la totalidad de los individuos que hacen parte de la clase no deben hacer presencia en la corte y no tienen control sobre el litigio. Es el representante de la clase quien actúa frente a un juez en nombre de ellos. De hecho, según las reglas de las acciones de clase estadounidenses, el representante puede vincular un individuo a una clase sin que sea necesaria su anuencia previa. Una vez notificado de que hace parte de una clase, el individuo puede optar por continuar en el litigio y beneficiarse eventualmente de la reparación ordenada por el juez, o salirse del mismo (opt out) y dejar de recibir los beneficios derivados de las posibles indemnizaciones ${ }^{2}$.

Las acciones de grupo colombianas siguen una lógica similar a las de las acciones de clase estadounidenses, ya que el apoderado o representante de un grupo de individuos agraviados por un daño particular (ambiental, de productos defectuosos, de servicios públicos, etc.) exige reparaciones concretas en nombre del grupo ante un tribunal.

Las acciones populares colombianas tienen una estructura distinta a la de las acciones de clase estadounidenses y las acciones de grupo consagradas en la Constitución de 1991. En primer lugar, las acciones populares no requieren la constitución de una clase o grupo de individuos agraviados. Por el contrario, las acciones populares se crearon para proteger de manera solidaria derechos e intereses

1 Deborah R. Hensler, The Globalization of Class Actions: An Overview, 622 The Annals of the American Academy of Political and Social Science, 1, 7-29 (2009). Disponible en: https://www. researchgate.net/publication/249666853_The_Globalization_of_Class_Actions_An_Overview

2 Deborah R. Hensler, Nick Pace, Bonnie Dombey-Moore, Elizabeth Giddens, Jennifer Gross \& Erik Moller, Class Action Dilemmas: Pursuing Public Goals for Private Gain (Rand Corporation, Santa Mónica, California, 2000). Disponible en: http://www.rand.org/pubs/monograph_reports/MR969. html. Deborah R. Hensler, The Future of Mass Litigation: Global Class Actions and Third-Party Litigation Funding, 79 George Washington Law Review, 2, 306-323 (2011). Disponible en: http:// www.gwlr.org/wp-content/uploads/2012/08/79-2-Hensler.pdf 
colectivos difusos - entre ellos, el medio ambiente- por parte de cualquier individuo o grupo de individuos. En este sentido, las acciones populares no buscan reparar el daño causado a un grupo de personas concreto, sino proteger un bien público o un recurso de uso común que beneficia a una colectividad difusa.

Siete años después de la expedición de la Constitución de 1991, el legislador reguló las acciones populares y de grupo por medio de la Ley 472 de $1998^{3}$. Según datos del Consejo Superior de la Judicatura, entre 1998 y 2009 el litigio de acciones populares experimentó tasas de crecimiento constantes ${ }^{4}$. Para 2009, los ingresos efectivos de acciones populares en los tribunales y juzgados administrativos del país ascendían a 19.887 casos, lo cual representaba un 3,90\% del total de acciones constitucionales presentadas en Colombia durante ese año ${ }^{5}$.

No obstante, sobre el litigio de acciones populares siempre se cernió la sospecha de que era promovido por litigantes temerarios que, en lugar de proteger de manera solidaria el interés general, buscaban lucrarse del incentivo económico creado por la Ley 472 de 1998. Pese a que la Corte Constitucional consideró, en el fallo C-459-04 ${ }^{6}$, que el incentivo económico para los actores populares era constitucional, varios comentaristas sugirieron que el gobierno nacional y el Congreso debían eliminar el incentivo económico pues este desfiguraba la naturaleza de las acciones populares al incluir un elemento de lucro ${ }^{7}$. Por el contrario, algunos autores sostuvieron que los incentivos económicos no debían ser eliminados de las acciones populares, ya que en muchos casos eran indispensables

3 Colombia, Ley 472 de 1998, por la cual se desarrolla el artículo 88 de la Constitución Política de Colombia en relación con el ejercicio de las acciones populares y de grupo y se dictan otras disposiciones, 43.357 Diario Oficial, 6 de agosto de 1998. Disponible en: http://www.secretariasenado. gov.co/senado/basedoc/ley_0472_1998.html

4 Corporación Excelencia en la Justicia, CEJ, Eliminación del incentivo económico reduce las acciones populares (2014). Disponible en: http://www.cej.org.co/index.php/justiciometros3/3897-eliminaciondel-incentivo-economico-reduce-las-acciones-populares

5 Corporación Excelencia en la Justicia, CEJ, Eliminación del incentivo económico reduce las acciones populares (2014).

6 Colombia, Corte Constitucional, Sentencia C-459-04, 11 de mayo de 2004, magistrado ponente Jaime Araújo-Rentería. Disponible en: http://www.corteconstitucional.gov.co/relatoria/2004/c-459-04.htm

7 Ramiro Bejarano, Los incentivos han muerto, Ámbito Jurídico (2012). Disponible en: https://www. ambitojuridico.com/BancoConocimiento/Educacion-y-Cultura/noti-120229-07-los-incentivos-hanmuerto.cshtml/ 
para financiar el litigio de interés público y la defensa de los derechos colectivos ${ }^{8}$.

La Ley 1425 de 2010 zanjó este debate al eliminar el incentivo económico o monetario para los actores populares ${ }^{9}$. La voluntad del legislador fue eliminar esos incentivos, ya que no eran un medio idóneo para promover la defensa de los intereses y derechos colectivos. Por el contrario, en sentir del legislador, los incentivos económicos podían promover el litigio oportunista de actores privados interesados en beneficiarse individualmente, mediante la promoción de litigios colectivos. Además, tanto el ejecutivo como el legislativo estuvieron de acuerdo con que el pago de los incentivos generó perjuicios a los presupuestos locales, para obligar a los municipios a dejar de invertir estos recursos en otras necesidades fundamentales de la población ${ }^{10}$.

Posteriormente, con el fallo C-630-11, la Corte Constitucional reversó el precedente creado en el fallo C-459-04 y declaró la constitucionalidad de la norma. De esta manera, se eliminaron definitivamente los incentivos económicos para el actor popular previstos en la Ley 472 de 1998 y derogados por la Ley 1425 de 2010. Para la Corte Constitucional, la ley derogatoria era exequible por cuatro razones: (i) la existencia del incentivo es parte del ejercicio de libertad de configuración legislativa del Congreso; (ii) el incen-

8 Rodrigo Uprimny, Las acciones populares ¿Impopulares en el Gobierno?, Semana (2 de septiembre de 2006). Disponible en: http://www.semana.com/opinion/articulo/las-acciones-popularesimpopulares-gobierno/80727-3

9 Colombia, Ley 1425 de 2010, por medio de la cual se derogan artículos de la Ley 472 de 1998 Acciones Populares y Grupo, 47.937 Diario Oficial, 29 de diciembre de 2010. Disponible en: http:// www.secretariasenado.gov.co/senado/basedoc/ley_1425_2010.html

10 Colombia, ponencia para primer debate al Proyecto de Ley 169 de 2010 Senado, 056 de 2009 Cámara, por medio de la cual se derogan algunos artículos de la Ley 472 de 1998 - Acciones Populares y de Grupo (Exposición de motivos Ley 1425/2010), 792/10 Gaceta del Congreso, 20 de octubre de 2010. Disponible en: http://www.imprenta.gov.co/gacetap/gaceta.nivel_3. Colombia, ponencia para segundo debate al Proyecto de Ley 169 de 2010 Senado, 056 de 2009 Cámara, por medio de la cual se derogan algunos artículos de la Ley 472 de 1998 - Acciones Populares y de Grupo (Exposición de motivos Ley 1425/2010), 885/10 Gaceta del Congreso, 11 de noviembre de 2010. Disponible en: http://www.imprenta.gov.co/gacetap/gaceta.nivel_3. Colombia, informe de conciliación al Proyecto de Ley 169 de 2010 Senado, 056 de 2009 Cámara, por medio de la cual se derogan algunos artículos de la Ley 472 de 1998 - Acciones Populares y de Grupo (Exposición de motivos Ley 1425/2010), 1082/10 Gaceta del Congreso, 13 de diciembre de 2010. Disponible en: http://www.imprenta.gov. co/gacetap/gaceta.nivel_3. Colombia, Texto definitivo aprobado en sesión plenaria al Proyecto de Ley 169 de 2010 Senado, 056 de 2009 Cámara, texto aprobado en sesión plenaria del Senado de la República del día 7 de diciembre de 2010 al Proyecto de Ley 169 de 2010 Senado, 056 de 2009 Cámara, por la cual se modifican algunos artículos de la Ley 472 de 1998 - Acciones Populares y de Grupo (Exposición de motivos Ley 1425/2010), 1118/10 Gaceta del Congreso, 22 de diciembre de 2010. Disponible en: http://www.imprenta.gov.co/gacetap/gaceta.nivel_3 
tivo no es esencial al espíritu de la acción popular, porque sigue existiendo la condena en costas, que garantiza la igualdad procesal entre demandantes y demandados; (iii) la razón de ser del incentivo era motivar a los actores populares, no el reconocimiento de sus gastos procesales; y (iv) la eliminación de incentivo no desdibuja la esencia de la acción popular ni es una medida regresiva de los derechos sociales económicos y culturales, porque su eliminación no genera problemas de acceso a la justicia para los actores populares ${ }^{11}$.

Según algunos autores, desde 2010, se ha producido un "desmonte" de las acciones populares en Colombia ${ }^{12}$. Este desmonte coincide, según estos autores, con la eliminación de los incentivos económicos para los actores populares por la Ley 1425 de 2010. Para estas voces críticas, la prueba "reina" del desmonte de las acciones populares está en el hecho de que tras la eliminación del incentivo económico las acciones populares interpuestas en el país disminuyeron dramáticamente. En efecto, según datos del Consejo Superior de la Judicatura, los volúmenes de acciones populares interpuestas ante juzgados y tribunales administrativos disminuyeron $77 \%$ entre 2009 y $2013^{13}$.

No obstante, ni los argumentos de la Corte Constitucional ni los del gobierno nacional estuvieron basados en estudios que evaluaran, con base en evidencia empírica, el impacto de los incentivos económicos sobre la calidad (oportunista o de interés público) del litigio de acciones populares. Esto no es sorprendente, ya que como lo muestra Hensler, en general hay muy poca evidencia empírica en esta área ${ }^{14}$. En otras palabras, no sabemos muy bien si el hecho de premiar con beneficios económicos al actor popular o representante en una acción de clase o grupo, promueve el interés general,

11 Colombia, Corte Constitucional, Sentencia C-630-11, 24 de agosto de 2011, magistrada ponente María Victoria Calle-Correa. Disponible en: http:/www.corteconstitucional.gov.co/relatoria/2011/c-630-11. htm

12 Beatriz Londoño-Toro \& María Lucía Torres-Villarreal, ¿Podrán las acciones populares colombianas sobrevivir a los recientes ataques legislativos y jurisprudenciales?, 124 Vniversitas, 235-259 (2012). Disponible en: http://revistas.javeriana.edu.co/index.php/vnijuri/article/ view/14299/11509

13 Corporación Excelencia en la Justicia, CEJ, Eliminación del incentivo económico reduce las acciones populares (2014). Disponible en: http://www.cej.org.co/index.php/justiciometros3/3897-eliminaciondel-incentivo-economico-reduce-las-acciones-populares

14 Deborah R. Hensler, The Future of Mass Litigation: Global Class Actions and Third-Party Litigation Funding, 79 George Washington Law Review, 2, 306-323 (2011). Disponible en: http://www. gwlr.org/wp-content/uploads/2012/08/79-2-Hensler.pdf 
o más bien promueve la búsqueda de rentas económicas por parte de los litigantes.

Este artículo se propone llenar dos vacíos sensibles en la literatura local sobre las acciones populares que protegen el medio ambiente. Por una parte, presentaremos un panorama comprehensivo de las acciones populares ambientales falladas por el Consejo de Estado durante el período 1998-2015. De este modo, el primer objetivo de esta investigación es describir el litigio de acciones populares ambientales en Colombia desde la perspectiva de los sujetos que han intervenido en estos procesos (tipos de demandantes y demandados); los distintos tipos de recursos ambientales protegidos por los fallos; la forma como han fallado los jueces, entre otras variables.

Por otra parte, este artículo of rece evidencia sobre el impacto de los incentivos económicos en el litigio de acciones populares entre los años 1998 y 2010, momento en el que la Ley 1425 de 2010 (declarada exequible por la Sentencia C-630-11) derogó los incentivos económicos para las acciones populares. Con base en esta evidencia, el artículo concluye que muchos de los argumentos esgrimidos por el gobierno nacional y algunos comentaristas para justificar la eliminación del incentivo económico en las acciones populares carecían de sustento empírico.

\section{METODOLOGÍA}

El primer paso de nuestra investigación consistió en identificar el universo de acciones populares decididas en el país en materia de medio ambiente. La Ley 472 de 1998, en su artículo 80, estableció que el Registro Público de Acciones Populares y de Grupo de la Defensoría del Pueblo contendría la información de las acciones populares y de grupo decididas por jueces de todas las instancias en el país. A pesar de esto, en la Defensoría del Pueblo reposa un bajísimo porcentaje de los casos efectivamente decididos por los jueces. Aún más, las acciones populares que alberga la Defensoría no están sistematizadas. Una de las conclusiones iniciales de nuestro trabajo de campo es que la ausencia de un registro nacional reduce considerablemente la posibilidad de estudiar la evolución y desarrollo de las acciones populares y de grupo en todo el país. Con esto, es difícil estudiar los avances en materia de litigio ambiental. 
Ante la imposibilidad de acceder a información centralizada sobre las acciones populares falladas por tribunales y juzgados administrativos, nos concentramos en los casos decididos por el Consejo de Estado en sede de apelación. Aunque las acciones populares medioambientales decididas por el Consejo de Estado no reflejan con completa fidelidad el litigio en todo el país, sí constituyen un proxy válido ante la ausencia de datos confiables en tribunales y juzgados administrativos.

Desde la aprobación de la Constitución de 1991, el Consejo de Estado ha decidido en segunda instancia 254 acciones populares en relación con el medio ambiente. Para identificar los 254 casos estudiados, utilizamos los descriptores "medio ambiente", "ambiente" y "ambiental", en el motor de búsqueda de la página web del Consejo de Estado. Nos concentramos solo en los casos en sede de apelación de sentencias, por considerar que estos casos nos permiten identificar el razonamiento de las partes y los jueces en relación con la protección del medio ambiente. Los casos conocidos en revisión eventual frecuentemente se concentran en aspectos procesales, por lo que no aportaban elementos suficientes para este estudio.

Este artículo utiliza un enfoque de análisis de contenido con base en un libro de códigos de veinte variables, las cuales guiaron nuestro análisis cualitativo y cuantitativo ${ }^{15}$. Un equipo de cuatro codificadores, que incluyen los investigadores principales, analizó los casos, teniendo como base el libro de códigos. Para garantizar la confiabilidad de la codificación (intercoder reliability), se condujo un estudio piloto de 30 casos y posteriormente se realizaron dos test de confiabilidad ${ }^{16}$. Al final de la etapa de codificación se implementó un test final de confiabilidad, que tuvo un resultado del $91 \%$, lo que supera por más de diez puntos el porcentaje de confiabilidad mínima recomendado por la literatura especializada.

15 Sobre análisis de contenido en relación con cortes: Mark A. HaLl \& Ronald F. Wright, Systematic Content Analysis of Judicial Opinions, 96 California Law Review, 1, 63-122 (2008). Disponible en: http://scholarship.law.berkeley.edu/cgi/viewcontent.cgi?article=1186\&context=californialawrev iew. En relación con test de confiabilidad: Matthew Lombard, Jennifer Snyder Duch \& Cheryl Campanella-Bracken, Content Analysis in Mass Communication: Assessment and Reporting of Intercoder Reliability, 28 Human Communication Research, 4, 587-604 (2002).

16 El primero de estos test dio como resultado una confiabilidad del $79 \%$. Después de este test se hicieron ajustes en la codificación y análisis de casos individuales, para unificar conceptos entre todos los codificadores. Finalmente, se condujo un segundo test con un resultado del $90 \%$ de confiabilidad. 
Las primeras variables estudiadas identifican información relativa a las partes de cada proceso. Cada caso se codificó de acuerdo a la información sobre demandantes, demandados y apelantes; en los casos con pluralidad de demandantes y demandados, también se codificó esta información.

Incluimos las variables "tipo de caso" y "otros derechos colectivos vulnerados en el caso" que nos permitieran estudiar los hechos que los demandantes identificaron como violaciones o daños al medio ambiente ${ }^{17}$. También analizamos el tipo de caso a la luz del impacto de la violación al medio ambiente. Clasificamos los tipos de violaciones según si eran violaciones ocasionadas por una política pública o si eran violaciones ocasionadas por decisiones individuales de funcionarios públicos.

Por otra parte, codificamos información relacionada con el incentivo económico o monetario que, de acuerdo con la Ley 472 de 1998, se concedía a los actores populares y que fue eliminado en 2010. Teniendo en cuenta que los casos en nuestra base de datos fueron iniciados entre 1998 y 2012, esta investigación arroja información de acciones populares iniciadas cuando el incentivo estaba vigente y una vez fue eliminado.

Específicamente, codificamos variables que podían determinar si el actor popular solicitó el incentivo, si el juez lo concedió y en qué monto fue concedido. Finalmente, incluimos una variable en relación con las costas, con miras a explorar si este mecanismo procesal ha sido utilizado por los jueces y las partes como un sustituto del incentivo económico, esto es, como un apoyo económico al trabajo y tiempo invertido en el proceso por parte del actor popular.

Analizamos también información en relación con el juez que proyectó la decisión en cada caso. Esa información, junto con la variable que denominamos "decisión", nos permitió explorar si las características del juez tienen algún impacto sobre la manera en que los casos son decididos. La variable "decisión" también nos permitió estudiar si hay alguna variación ocasionada por el tipo

17 Al codificar el tipo de violación a la que se refiere el caso, pudimos concentrarnos en aquellos casos en los que realmente estaba en tela de juicio una violación al medio ambiente. No se tuvieron en cuenta aquellos casos en los que, si bien se hizo mención al medio ambiente, la discusión se concentraba en transgresiones a otros derechos colectivos inconexos. 
de demandante o demandado sobre la decisión de los consejeros de Estado.

Por último, condujimos un análisis cualitativo de las sentencias, con base en códigos que nos permitieron identificar temáticas comunes entre los casos. En nuestro análisis, presentamos información de estos códigos, en especial en lo relativo a las narrativas sobre el incentivo económico desarrolladas por el Consejo de Estado y las partes.

\section{RESULTADOS}

\section{A. Año de inicio del proceso y de decisión del caso}

El año de inicio es relevante para nuestro estudio, porque nos permitió explorar desde qué año empezaron a usarse las acciones populares en protección del medio ambiente y si hubo cambios en el uso de este mecanismo a lo largo del período 1998-2015.

Los casos analizados evidencian que las acciones populares medioambientales fueron empleadas a partir de 1998. En 1998 y 1999 tan solo se promovieron seis (6) acciones populares de este tipo, que representan el 2,4\% de los casos estudiados. A partir del año 2000, el número de acciones iniciadas aumentó considerablemente, de tal suerte que en el año 2000 se interpuso cerca del 17\% de todos los casos estudiados. La mayoría de las acciones populares analizadas se interpuso en 2001 y 2003. Después de 2004, el número de acciones populares instauradas descendió considerablemente (gráfico 1). Analizaremos las implicaciones de estas estadísticas en la sección atinente al incentivo económico. 


\section{Gráfico 1}

Año de inicio del proceso

\begin{tabular}{|c|c|}
\hline Año & Porcentaje (\%) \\
\hline 1998 & 0,40 \\
\hline 1999 & 2,00 \\
\hline 2000 & 16,73 \\
\hline 2001 & 17,93 \\
\hline 2002 & 14,34 \\
\hline 2003 & 18,33 \\
\hline 2004 & 16,33 \\
\hline 2005 & 6,77 \\
\hline 2006 & 0,80 \\
\hline 2009 & 0,80 \\
\hline 2010 & 1,20 \\
\hline 2011 & 3,20 \\
\hline 2012 & 1,20 \\
\hline Total & 100,00 \\
\hline
\end{tabular}

$\mathrm{N}=251$

Fuente: elaboración propia

Al explorar el año de decisión del proceso por parte del Consejo de Estado, encontramos que los casos fueron decididos entre el año 2000 y el año 2015 (gráfico 2). En 2001 se decidieron cerca del $15 \%$ de todos los casos estudiados. Este resultado sorprendente para 2001 no parece obedecer a factores políticos o legislativos en el país o de orden administrativo dentro del Consejo de Estado ${ }^{18}$.

18 El año 2001 no coincide con elecciones presidenciales ni con la aprobación de legislación en materia de acciones populares ambientales. El Consejo de Estado tampoco profirió normativa que explique el aumento en el número de casos decididos. A pesar de lo anterior, en 2001, el Consejo de Estado decidió un número más alto de acciones populares, no solo en materia medioambiental sino también en relación con el derecho colectivo a la moralidad administrativa. 


\section{Gráfico 2}

Año de decisión del proceso. $N=254$

\begin{tabular}{|c|c|}
\hline Año & Porcentaje (\%) \\
\hline 2000 & 8,27 \\
\hline 2001 & 14,96 \\
\hline 2002 & 6,30 \\
\hline 2003 & 6,30 \\
\hline 2004 & 8,66 \\
\hline 2005 & 3,15 \\
\hline 2006 & 7,48 \\
\hline 2007 & 7,48 \\
\hline 2008 & 7,09 \\
\hline 2009 & 9,06 \\
\hline 2010 & 7,48 \\
\hline 2011 & 5,11 \\
\hline 2012 & 2,76 \\
\hline 2013 & 3,54 \\
\hline 2014 & 0,79 \\
\hline 2015 & 1,57 \\
\hline Total & 100 \\
\hline & \\
\hline
\end{tabular}

Fuente: elaboración propia

\section{B. Incentivo económico y costas}

Como lo mostró en su momento el Consejo Superior de la Judicatura, tras la eliminación del incentivo económico por la Ley 1425 de 2010, el litigio de acciones populares experimentó un descenso marcado. Entre 2009 y 2013, los ingresos de acciones populares a los tribunales y juzgados administrativos del país cayeron en $77 \%$. Mientras en 2009 se radicaron ante los tribunales administrativos 19.887 acciones populares, en 2013 se radicaron apenas $4.506^{19}$.

No obstante, nuestra base de datos, compuesta por acciones populares falladas por el Consejo de Estado — no por juzgados

19 Corporación Excelencia en la Justicia, CEJ, Balance de los 10 años de las acciones populares y de grupo (Corporación Excelencia en la Justicia, CEJ, Bogotá, 2008). Disponible en: http://www.cej. org.co/index.php/component/docman/doc_download/147-balance-de-los-10-anos-de-las-accionespopulares-y-de-grupo?Itemid=59 
y tribunales administrativos-, no muestra un descenso en el número de acciones populares interpuestas por los litigantes tras la eliminación del incentivo económico en 2010. Por el contrario, mientras en 2009 se inició un $0,8 \%$ del total de casos analizados, en 2010 se inició un 1,2\% y en 2011 un 3,2\% (gráfico 1). Una forma de leer esta tendencia es que en el Consejo de Estado el descenso en el número de acciones populares se experimentó antes que en los juzgados y tribunales administrativos. Más concretamente, el declive de las acciones populares iniciadas en nuestro universo de casos se dio entre 2004 y 2006, cuando el porcentaje de acciones populares iniciadas pasó de 6,77\% en 2005 a 0,8\% en 2006 (gráfico 1). Así, el uso de las acciones populares para proteger el medio ambiente descendió desde 2004, por factores que aún no son claros.

Una hipótesis que explica el descenso en el volumen de acciones populares que llegaron hasta el Consejo de Estado es la creación y entrada en funcionamiento, en marzo de 2006, de 257 juzgados administrativos en todo el país ${ }^{20}$. El objetivo principal tras la apertura de los nuevos juzgados era que estos asumieran el $73 \%$ de la carga litigiosa que hasta ese momento recaía principalmente sobre los tribunales administrativos y secundariamente sobre el Consejo de Estado. La entrada en funcionamiento de los juzgados administrativos explica el descenso en el número de acciones populares desde 2006, pero no es claro aún el descenso que se produjo desde 2004. Este aspecto del desarrollo del litigio colectivo ambiental en Colombia deberá ser analizado en el futuro.

Si bien desde la perspectiva del análisis cuantitativo no es posible afirmar que la eliminación del incentivo económico en 2010 generó un descenso en el número de acciones populares iniciadas ante el Consejo de Estado, nuestra base de datos sí arroja resultados interesantes sobre el impacto que tuvo el incentivo económico en el litigio de acciones populares durante el período 1998-2010.

Al analizar nuestro universo de casos, encontramos que los actores populares solicitaron el incentivo como una de las pretensiones

20 Colombia, Consejo Superior de la Judicatura, Acuerdo PSAA06-3333 de 2006, por el cual se autorizan unos ajustes en el presupuesto de funcionamiento de la rama judicial, XIII Gaceta de la Judicatura, Extraordinaria No. 08, 2 de marzo de 2006. Disponible en: http://200.74.133.188/csj_portal/assets/ EXTRA08-06.pdf 
de la demanda en el 76\% de los casos (gráfico 3) ${ }^{21}$. El Consejo de Estado lo concedió en menos de la mitad de los casos (49\%, gráfico 4).

Uno de los hallazgos de nuestro estudio es que a pesar de que los actores populares solicitaron el incentivo con frecuencia, el Consejo de Estado lo concedió tan solo en menos de la mitad de los casos. El análisis cualitativo de los fallos muestra que el Consejo de Estado concedió el incentivo cuando el accionante había logrado demostrar un daño al medio ambiente atribuible al demandado, excepto: i) cuando la entidad demandada demostraba que había iniciado gestiones para solucionar la situación problemática - a veces, aunque esto hubiera ocurrido después de la notificación de la acción popular en su contra-; ii) cuando el proceso terminaba con pacto de cumplimiento favorable a los intereses del accionante en vez de sentencia condenatoria. En estos casos, el actor no recibió el incentivo económico solicitado en la demanda.

En ocasiones, la amenaza de afectación al ambiente no fue suficiente para obtener un fallo favorable al accionante y el consecuente reconocimiento del incentivo. En estos casos, los jueces optaron por no fallar a favor de los accionantes y reconocer el incentivo, sino que se limitaron a exhortar a las entidades públicas a tomar medidas preventivas ${ }^{22}$.

En algunos procesos, el demandante logró probar una afectación al medio ambiente atribuible a una entidad pública demandada, pero esta demostró no tener disponibilidad presupuestal para emprender las acciones protectoras que se le exigían. En estos casos, el Consejo de Estado declaró la violación del derecho colectivo y concedió el incentivo económico ${ }^{23}$.

21 Para codificar esta variable, tuvimos como base los hechos y pretensiones de las demandas como constan en las sentencias de apelación del Consejo de Estado. Es decir, solo contamos los fallos que expresamente mencionaban la solicitud del incentivo en los antecedentes. Los casos en los que no se menciona si hubo o no solicitud del incentivo en la demanda fueron codificados como sin solicitud de incentivo.

22 Colombia, Consejo de Estado, Radicación 68001-23-15-000-20030052101, 22 de enero de 2009, consejero ponente Marco Antonio Velilla-Moreno. En este caso, Alicia Gaviria-Rondón contra el municipio de Bucaramanga y otros, sobre edificaciones en alto riesgo de ruina o desastre, tanto en primera como en segunda instancia se negaron las pretensiones, porque no se logró demostrar el daño o vulneración de derechos. Pero es interesante que tanto el Tribunal como el Consejo de Estado por razones preventivas exhortaron a las entidades demandadas a realizar los estudios técnicos necesarios y a proceder según estos indicaran. Los demandantes no ganaron la acción popular ni se les reconoció el incentivo económico, pero lograron visibilizar una amenaza a la seguridad pública y destrabar el nudo institucional que impedía la toma de medidas para la prevención de un desastre.

23 La falta de disponibilidad presupuestal no fue considerada una causal excluyente de la responsabi- 
Adicionalmente, al explorar los montos en que el incentivo fue concedido, encontramos que en casi la totalidad de los casos (93\%) el juez otorgó el mínimo dentro del rango definido en la ley, es decir, 10 salarios mínimos mensuales ${ }^{24}$. Este panorama dista del descrito por el gobierno nacional y por algunos comentaristas, según los cuales el incentivo económico había desfigurado las acciones populares y las había convertido en mecanismos para que algunos individuos temerarios se lucraran a costa del erario ${ }^{25}$.

La acción popular de radicación 0001-23-31-000-2004-00972-01 es un ejemplo de esta tendencia. En este caso, el ciudadano Alexander José Farías demandó al municipio de Sampués y la Corporación Autónoma Regional de Sucre con la pretensión de que se ordenara la construcción de lagunas de estabilización y tratamiento de aguas residuales en el municipio. También solicitó al juez que se concediera el incentivo a que hubiera lugar. El Consejo de Estado confirmó lo decidido por el Tribunal al ordenar al municipio la construcción del sistema de vertimientos de aguas residuales. También ordenó a la Corporación Autónoma Regional controlar, evaluar y hacer seguimiento al vertimiento de residuos líquidos para evitar daños al desarrollo sostenible de los recursos naturales. Finalmente, se reconoció el incentivo a favor del accionante equivalente a diez salarios mínimos legales mensuales vigentes ${ }^{26}$. Teniendo en cuenta que la sentencia del Consejo de Estado se profirió en 2008 esta suma corresponde a $\$ 4.615 .000$.

lidad de los municipios. El Consejo de Estado argumentó que, por el contrario, la falta de recursos confirmaba la situación de violación de los derechos colectivos relacionados con el ambiente sano.

Artículo 39 y 40, Ley 472 de 1998, derogados por la Ley 1425 de 2010.

25 Ramiro Bejarano, Los incentivos han muerto, Ámbito Jurídico (2012). Disponible en: https://www. ambitojuridico.com/BancoConocimiento/Educacion-y-Cultura/noti-120229-07-los-incentivos-hanmuerto.cshtml/

26 Colombia, Consejo de Estado, Radicación 0001-23-31-000-2004-00972-01(AP), 4 de diciembre de 2008, consejero ponente Marco Antonio Velilla-Moreno. 


\section{Gráfico 3}

Solicitud de incentivo por parte del actor popular. $N=\mathbf{2 5 4}$

¿Actor pidió incentivo?

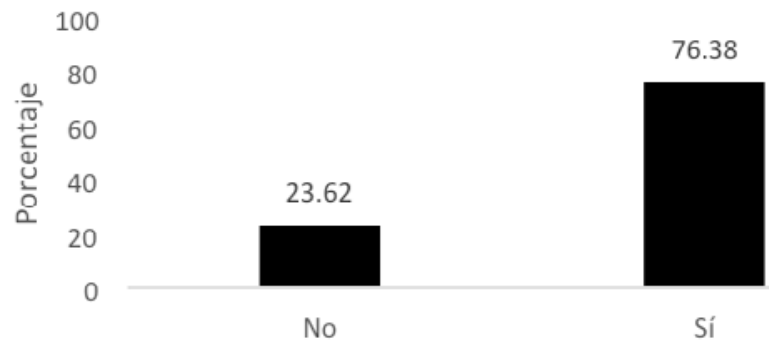

Fuente: elaboración propia

\section{Gráfico 4}

Decisión del Consejo de Estado en relación con el incentivo. $N=254$

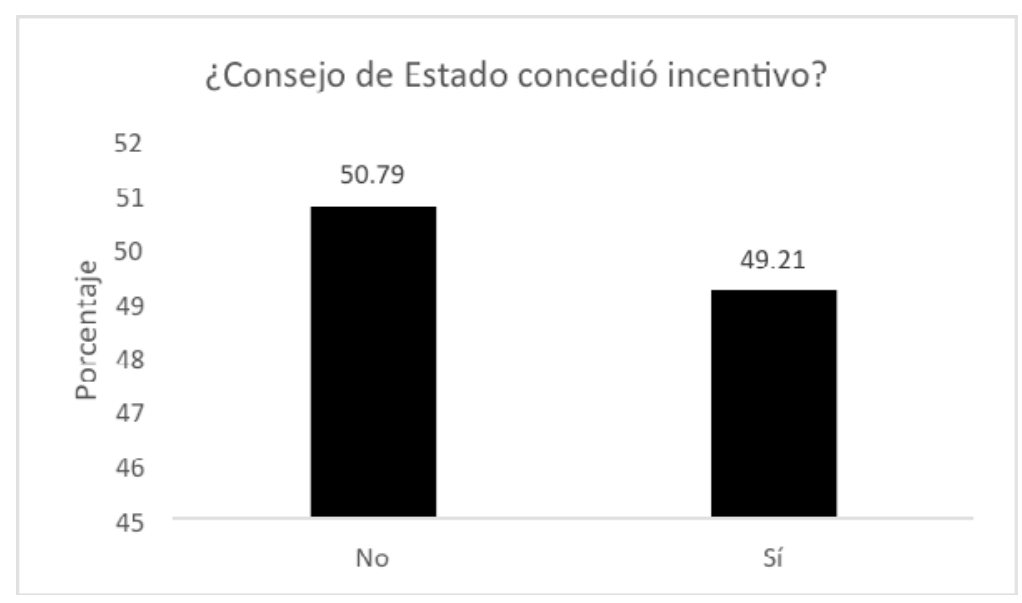

Fuente: elaboración propia 


\section{Gráfico 5}

Monto del incentivo concedido. $N=119$

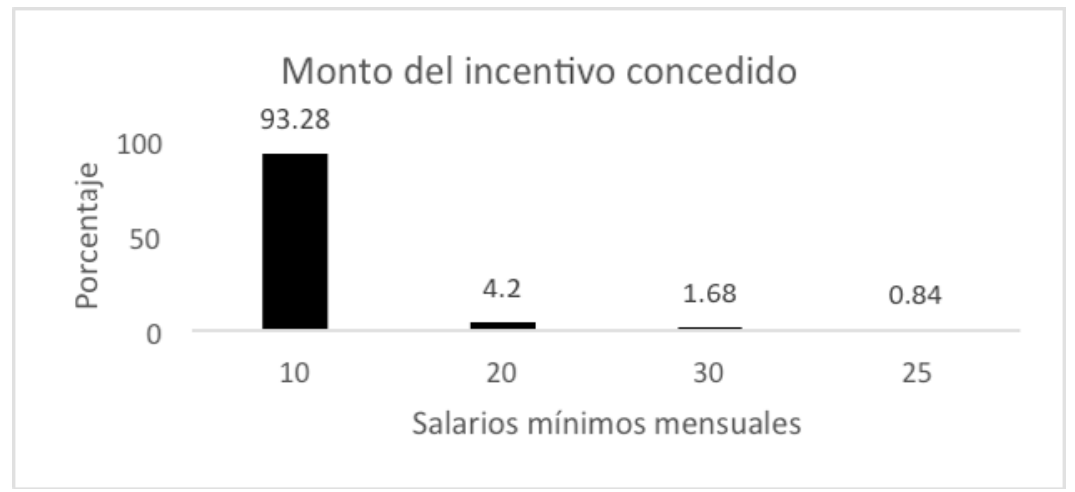

Fuente: elaboración propia

\section{Constitucionalidad de la ley derogatoria del incentivo económico}

En la demanda de inconstitucionalidad que se presentó ante la Corte Constitucional contra la ley derogatoria del incentivo se discutió que eliminarlo constituía una violación del principio de igualdad procesal, porque desprotegía al actor popular que estaba en inferioridad frente a la gran capacidad económica y política de los demandados. Uno de los argumentos principales expuestos por la Corte Constitucional en la sentencia C-630-11 en favor de la exequibilidad de la Ley, fue que la razón de su existencia no era reconocerle al actor popular los gastos procesales en que había incurrido, sino incentivar o motivar el uso de la acción popular, por lo que al eliminarlo no se podía estar poniendo en desventaja procesal al demandante. Para la Corte, la derogación del incentivo económico no era entonces desproporcionada o irrazonable, porque al reconocerle las costas al actor, se garantizaba el equilibrio de las partes en el proceso ${ }^{27}$.

27 El monto de las agencias en derecho para acciones populares (que solo se reconocen a los abogados y no a los demás actores populares) es de entre dos y cuatro salarios mínimos mensuales legales vigentes. Las costas no se reconocen cuando el proceso de acción popular termina con pacto de cumplimiento. 
La Corte aceptó que no reconocer a las personas los gastos en los que incurrieran para adelantar un proceso constitucional sí implicaría imponerles un costo a su patrimonio y con ello, una desventaja. Argumentó que la eliminación del incentivo solo se podía tener como inconstitucional si se hubiera demostrado que conllevaba la supresión de la posibilidad de compensar a los actores populares en los costos en que hubieran incurrido. En la sentencia C-630-11, la Corte no encontró probada esta supresión de la compensación debida a los actores populares ${ }^{28}$.

Con miras a explorar si las costas han sido utilizadas como mecanismo procesal por las partes o los jueces como un posible reemplazo del incentivo económico, codificamos esta información en los casos analizados. Encontramos que tan solo en el 3\% de los casos el juez concedió costas a los actores populares, por lo que no es posible afirmar que los demandantes hayan percibido compensación o provecho económico por este medio.

No es sorprendente pues, que la eliminación de los incentivos económicos en 2010 y la bajísima posibilidad de que el Consejo de Estado otorgue costas han impactado de manera negativa el litigio de interés público en materia de acciones populares ambientales. En entrevistas con funcionarios administrativos, judiciales y de órganos de control, encontramos la percepción reiterada de que el uso de las acciones populares disminuyó con la eliminación del incentivo. Órganos de control como la Procuraduría y la Defensoría han entendido que ahora una de sus funciones es suplir lo que los ciudadanos no hagan como actores populares, porque no cuentan con el respaldo financiero del incentivo ${ }^{29}$.

28 Colombia, Corte Constitucional, Sentencia C-630-11, 24 de agosto de 2011, magistrada ponente María Victoria Calle-Correa.

29 Entrevista servidor público Andrés, Bogotá, Distrito, 6 de julio de 2012, Bogotá - Colombia. Entrevistadora: Ángela M. Páez M. Entrevista defensora delegada Camila, Defensoría del Pueblo, 30 de mayo de 2015, Bogotá, Colombia. Entrevistadora: Ángela M. Páez M. Entrevista funcionario de nivel ejecutivo Procuraduría General de la Nación Carlos, 5 de mayo de 2014, Bogotá, Colombia. Entrevistadora: Ángela M. Páez M. El nombre de los entrevistados se cambió por seudónimos. 


\section{Las partes procesales: \\ demandantes y demandados}

En relación con las partes involucradas en acciones populares por violaciones o daños al medio ambiente, encontramos que en su mayoría, los demandantes son individuos ${ }^{30}(76 \%$, gráfico 6$)$, mientras que los demandados son gobiernos locales o entidades del orden local $(72 \%$, gráfico 7$)$. La participación de organizaciones de la sociedad civil (asociaciones de vecinos, ONG nacionales o transnacionales) como demandantes ha sido porcentualmente baja $(16,9 \%)$, lo que evidencia que las organizaciones de la sociedad civil no utilizan con frecuencia las acciones populares como mecanismo de protección del medio ambiente. De los individuos que actuaron como demandantes, en su mayoría, son hombres $(58 \%$ de todos los demandantes) en comparación con un 18\% de las demandas interpuestas por mujeres.

\section{Gráfico 6}

\section{Demandante principal. $\mathbf{N}=254$}

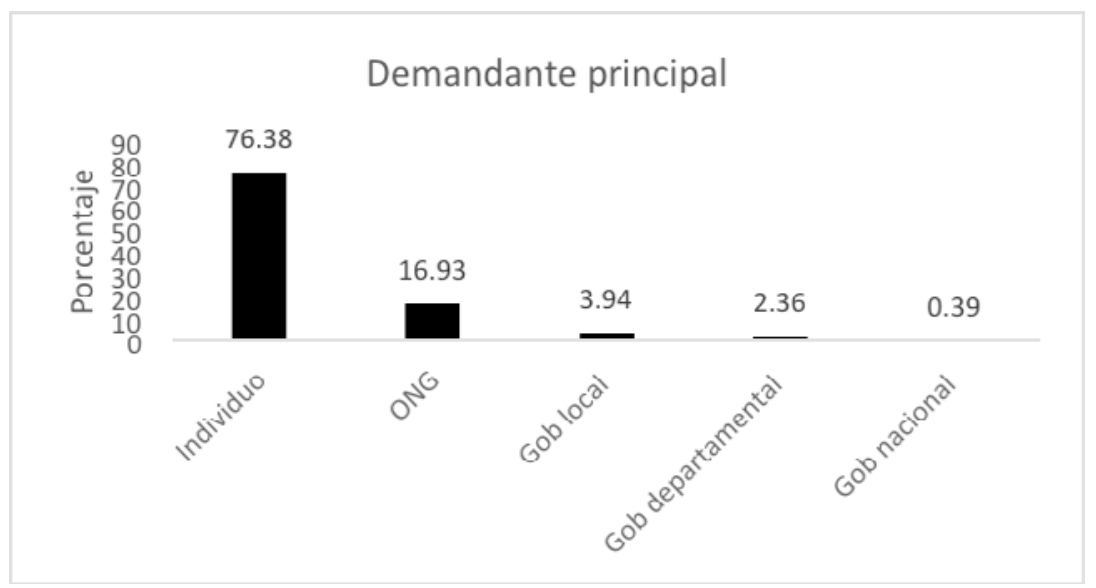

Fuente: elaboración propia

30 E1 73\% de los casos tenía demandante único. En el 27\% restante, la variable "Demandante 1" se codificó teniendo en cuenta quién fue el demandante principal, de acuerdo a los hechos del caso. En este $27 \%$ de casos, el segundo demandante fue un individuo, lo que confirma la tendencia de que quienes han utilizado las acciones populares en materia de medio ambiente han sido principalmente individuos. 
En los casos analizados, encontramos tres entidades públicas que fueron frecuentemente demandadas por violaciones al medio ambiente $^{31}$. Estas entidades son: el Distrito de Bogotá (13 casos), el Ministerio de Ambiente y Desarrollo Sostenible (12 casos) y el Municipio de Bucaramanga (11 casos).

Los casos en los que el Distrito de Bogotá ha sido demandado se concentran principalmente en la protección de un recurso natural como el aire o el agua. Un ejemplo de estos casos es la acción popular AP150 de 2001 (CE-SEC1-EXP2001-NAP150), instaurada por la Defensoría del Pueblo en contra del Distrito de Bogotá por la tala masiva de árboles en la ciudad. El Consejo de Estado en sede de apelación falló a favor del Distrito por cuanto consideró que, de acuerdo a las pruebas aportadas, el Distrito no había talado árboles de manera indiscriminada, sino que lo hizo en ejecución del plan denominado "Bogotá se viste de verde". En opinión del Consejo de Estado, este programa es la expresión de la organización que debe existir en todo municipio para proteger su medio ambiente.

De los 12 casos instaurados en contra del Ministerio de Ambiente y Desarrollo Sostenible, cuatro buscaban una reparación tras la afectación a recursos naturales. Otras pretensiones invocadas fueron la reducción del impacto ambiental ocasionado por grandes obras de infraestructura en el país, la protección de animales y vulneraciones a la salud pública.

Un ejemplo de protección de animales es la acción popular AP194 de 2001, en la que cuatro particulares demandaron al Ministerio de Ambiente con el alegato de que en marzo de 2000 se exportaron irregularmente cien mil kilogramos de carne de chigüiro correspondiente a diez mil ejemplares que fueron extraídos de la Orinoquía. La acción buscaba la declaración de responsabilidad del Ministerio por estos hechos, debido a que esta entidad autorizó la exportación de la carne de chigüiro. Afirmó el Ministerio en dicho concepto que el chigüiro no estaba registrado como especie en vía de extinción en los apéndices de la Convención sobre Comercio Internacional

31 La variación en las partes demandadas es grande, de tal suerte que las entidades más frecuentemente demandadas representan, de manera individual, entre el 2 y el 5\% del universo de casos. Si bien son porcentajes pequeños, se mencionan en este análisis por cuanto, teniendo en cuenta la variación, una categoría que represente cinco casos o más representa una entidad que ha sido demandada por violación al mismo derecho colectivo en repetidas ocasiones. 
de Especies Amenazadas de Fauna y Flora Silvestres ${ }^{32}$. El Consejo de Estado confirmó la sentencia de segunda instancia y accedió a las pretensiones de la demanda al considerar que si bien el chigüiro no era considerado una especie en vía de extinción, sí debía ser protegido de explotación indebida. Por esta razón, declaró la responsabilidad del Ministerio del Ambiente y de la Corporación Autónoma Regional de la Orinoquía ${ }^{33}$.

Los casos en contra del Municipio de Bucaramanga versan sobre la protección del medio ambiente en relación con diferentes temas, como: contaminación visual, espacio público y desarrollo de vivienda. Por ejemplo, en la acción de referencia 68001-23-15-0002001-2243-02 del 16 de enero de 2003, la Junta de Acción Comunal del barrio Malpaso demandó al Municipio de Bucaramanga por haber aprobado la construcción de nuevas urbanizaciones en el barrio Malpaso, que no cuenta con vías apropiadas para garantizar el acceso de medios de transporte adecuados para atender las necesidades de la comunidad. Esta negligencia del municipio, afirman los demandantes, afecta el medio ambiente. El Consejo de Estado falló a favor del demandante por considerar probadas las vulneraciones al medio ambiente y otros derechos colectivos en la medida en que la falta de vías de acceso adecuadas generó un impacto ambiental negativo por la emisión de gases y por contaminación sonora.

32 Unión Internacional para la Conservación de la Naturaleza, International Union for Conservation of Nature, IUCN, Convención sobre Comercio Internacional de Especies Amenazadas de Fauna y Flora Silvestres, firmada en Washington el 3 de marzo de 1973. Disponible en: https://cites.org/esp/ disc/text.php, http://www.alcaldiabogota.gov.co/sisjur/normas/Norma1.jsp?i=45530 AP194 de 2001. 


\section{Gráfico 7}

Demandado principal. $\mathbf{N}=\mathbf{2 5 4}$

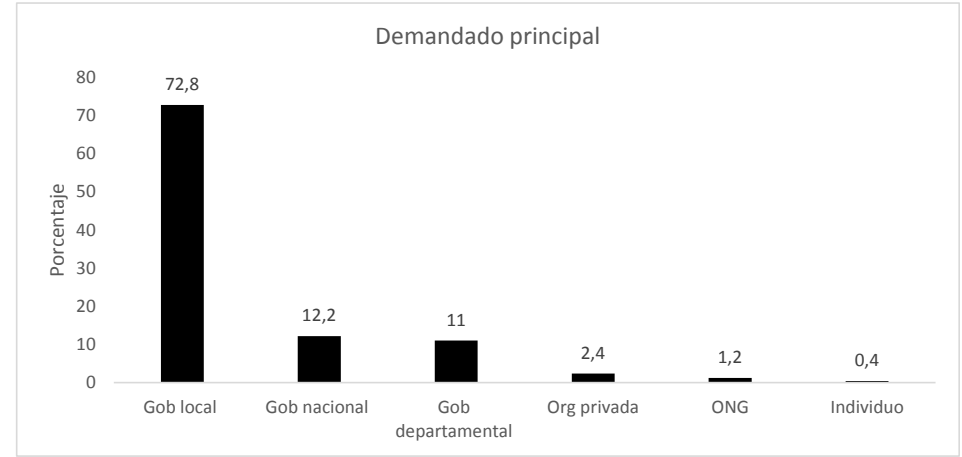

Fuente: elaboración propia

En el 64\% de los casos analizados se vinculó a un segundo demandado. En estos casos, el 49\% fueron municipios o entidades del orden local, el 21\% fueron departamentos o entidades del orden departamental, mientras que el 17\% fue el gobierno nacional o entidades del orden nacional.

\section{E. Litigantes recurrentes e incentivo económico}

En nuestro análisis también encontramos algunos litigantes que se dedicaron a demandar sistemáticamente violaciones al medio ambiente que se repetían en diferentes municipios del país. Si bien las demandas interpuestas por estos actores no corresponden a un porcentaje considerable en el universo de casos analizados, vale la pena resaltar que sí hay demandantes con características similares a las de los litigantes recurrentes (repeat players) descritos por Marc Galanter para el caso estadounidense ${ }^{34}$.

Este número limitado de litigantes recurrentes, asociados por algunos comentaristas con el litigio temerario ${ }^{35}$, descalifica la po-

34 Marc Galanter, Why the "Haves" Come out Ahead: Speculations on the Limits of Legal Change, 9 Law \& Society Review, 1, 95-160 (1974). Disponible en: http://jan.ucc.nau.edu/ phelps/Galanter\%20 1974.pdf

35 Ramiro Bejarano, Los incentivos han muerto, Ámbito Jurídico (2012). Disponible en: https://www. ambitojuridico.com/BancoConocimiento/Educacion-y-Cultura/noti-120229-07-los-incentivos-hanmuerto.cshtml/ 
sición defendida por quienes afirmaban que había un gran número de litigantes oportunistas dedicados a entablar acciones populares de manera recurrente e irresponsable para obtener el lucro económico derivado del incentivo. Nuestro análisis muestra que estos litigantes recurrentes eran, por el contrario, muy pocos, y que por lo demás no se dedicaban a entablar acciones populares temerarias, sino enfocadas a la protección del derecho a la salubridad pública y el medio ambiente sano, en temas concretos como la ausencia de instalaciones forenses en muchos municipios. Adicionalmente, los tribunales administrativos y el Consejo de Estado tendían a concederles incentivos económicos muy bajos, lo cual deja sin sustento el argumento según el cual estos actores se enriquecían a costa del erario.

Al sistematizar nuestro universo de casos, encontramos que algunos temas se repetían en lo que parecía ser la presentación recurrente de acciones por las mismas pretensiones - algunas veces por los mismos litigantes - en diferentes municipios del país. Se trata de solicitudes de aplicación de normas ya existentes de protección ambiental. En los departamentos de Huila y Quindío se presentaron acciones populares en casi todos sus municipios por los mismos actores populares en temas recurrentes.

Ejemplos de las pretensiones en los casos recurrentes en el país son: la construcción de salas de necropsia en los cementerios municipales que cumplieran los requisitos mínimos para garantizar la salubridad pública; la construcción, mantenimiento y adecuación de puentes peatonales desatendidos que se han convertido en focos de contaminación por acumulación de basuras y que no reúnen los requisitos de accesibilidad para personas con movilidad reducida; la remoción de vallas publicitarias no autorizadas que producen contaminación visual; la construcción y mejoramiento del sistema municipal de manejo de aguas (acueducto y alcantarillado), cuyo estado genera contaminación y problemas de salubridad pública; la construcción y mejoramiento de un sistema municipal de disposición final de basuras (relleno sanitario); y la construcción y adecuación de mataderos municipales que cumplan los requisitos legales para garantizar la salubridad pública.

Una forma de defensa que usaron los municipios demandados en estos casos recurrentes fue proponer la excepción preliminar de 
falta de legitimación en la causa por activa. Esta excepción consiste en descalificar la aptitud del accionante en el proceso judicial por no tener un interés legítimo en la causa.

Por ejemplo, en dos acciones populares presentadas contra el municipio de Pijao (Quindío) por servicios deficientes de alcantarillado y acueducto, los fallos de primera instancia fueron desfavorables al actor popular sin que se estudiaran sus argumentos de fondo ${ }^{36}$. La defensa del accionado - que aceptó el Tribunal Administrativofue que, al no vivir en el municipio demandado, el accionante no sufría una afectación por la situación de insalubridad que denunciaba. Además, que al haber interpuesto de manera recurrente la misma acción popular contra varios municipios, se podía concluir que se trataba de una demanda temeraria con la que el actor popular buscaba un interés particular (obtener el incentivo económico) y no el interés colectivo.

Pero los actores populares que apelaron estos fallos encontraron una respuesta diferente del Consejo de Estado. Los magistrados sostuvieron que al tratarse de derechos colectivos, cualquier ciudadano estaba legitimado para solicitar su protección y defensa y que, entonces, era procedente analizar el fondo de las acciones populares. En la mayoría de casos, el Consejo de Estado encontró que sí se había demostrado una afectación ambiental atribuible a la entidad demandada, revocó los fallos de primera instancia y reconoció el incentivo económico al actor.

Otro argumento que usaron los municipios demandados en este tipo de casos recurrentes fue la improcedencia de la Acción Popular. Si lo que se pedía era el cumplimiento de una norma, la procedente sería la Acción de Cumplimiento, sostenían. El Consejo de Estado concluyó que la Ley 472 de 1998 no consagraba como causal de improcedencia de la acción popular la existencia de otro mecanismo de defensa judicial. Adicionalmente, el Consejo de Estado sostuvo que aunque hubiera otro mecanismo idóneo para conseguir que la administración construya o ejecute una obra, cuando se trata de

36 Colombia, Consejo de Estado, Radicación 63001-23-31-000-2001-0293-01, 7 de diciembre de 2001, consejero ponente Darío Quiñones-Pinilla, Néstor Gregory Díaz-Rodríguez contra el municipio de Pijao. 
proteger un derecho colectivo se deben adoptar las medidas necesarias para hacer cesar los efectos de la vulneración ${ }^{37}$.

En conclusión, el análisis de nuestro universo de casos muestra que sí hubo actores que entablaban acciones recurrentes, frente a los cuales las entidades demandadas se defendieron alegando excepciones netamente procesales como la falta de legitimación en la causa por activa y la improcedencia de la acción. No obstante, el Consejo de Estado tendió a darles la razón a los demandantes recurrentes, a permitirles actuar en defensa del derecho colectivo y a reconocerles el monto mínimo de incentivo económico.

\section{F. Temática del litigio: derechos o recursos afectados por el daño ambiental}

En todas las acciones populares analizadas, los demandantes buscaban la protección del derecho colectivo al medio ambiente. Sin embargo, la variable "Tema" (gráfico 8) nos permitió identificar qué tipo de protección pretendían los demandantes ${ }^{38}$. En el 25\% de los casos, los demandantes denunciaron vulneraciones al medio ambiente que desencadenaron una afectación a la salud pública. En el 16\% de los casos, los actores populares exigían la protección de

37 Otro caso que ejemplifica esta tendencia es el de radicación 63001-23-31-000-2001-0314-01, de Néstor Gregory Díaz-Rodríguez contra el Municipio de Calarcá, en primera instancia el Tribunal Administrativo de Quindío negó las pretensiones y acusó directamente al accionante de tener un interés particular en el incentivo económico. Sin embargo, no lo sancionaron, condenaron en costas, ni usaron las herramientas procesales que ofrece la ley para sancionar a los demandantes temerarios. En la apelación, el actor alegó que la ley le ordenaba a cada municipio tener salas de necropsia que reunieran ciertos requisitos para garantizar la salubridad pública y que el Municipio de Calarcá no la tenía. Además, que cualquier persona podía usar la acción popular. El Consejo de Estado no solo lo consideró un actor legítimo, sino que aceptó la procedencia de la acción popular en este tipo de casos, por cuanto la Ley 472 de 1998 no consagra como causal de improcedencia la existencia de otro mecanismo de defensa judicial que, para el caso en concreto, correspondería a la acción de cumplimiento de que trata la Ley 393 de 1997. Se declaró la violación de derechos por parte del municipio y se le reconoció el incentivo al actor. Colombia, Consejo de Estado, Radicación 63001-23-31-000-2001-0314-01, 7 de diciembre de 2001, consejero ponente Darío Quiñones-Pinilla. Colombia, Ley 393 de 1997, por la cual se desarrolla el artículo 87 de la Constitución Política, 43.096 Diario Oficial, 30 de julio de 1997. Disponible en: http://www.secretariasenado.gov.co/senado/ basedoc/ley_0393_1997.html

38 Para codificar la variable "Tema", tuvimos en cuenta el objeto de protección perseguido por el actor popular y la valoración del problema jurídico por parte del Consejo de Estado. El objetivo de esta variable es identificar cómo se ha conceptualizado el derecho colectivo al medio ambiente. De manera particular, nos concentramos en qué bienes se han protegido por acciones populares medioambientales y qué prestaciones se han perseguido para garantizar su protección. En algunos casos convergieron diferentes categorías. La codificación se hizo con base en la pretensión principal del actor y las consideraciones del Consejo de Estado. 
un recurso natural (agua, aire, suelo) que estaba siendo dañado, sin que este daño estuviera vinculado directamente con vulneraciones a la vida o salud de la población.

El 11\% de los casos se concentró en problemas de infraestructura del país, los cuales estaban teniendo un impacto negativo en el medio ambiente. Las demás categorías representan menos del 10\% de los casos. Entre estas categorías están: casos relacionados con sistemas de alcantarillado, espacio público, servicios públicos, seguridad pública, manejo de desechos, contaminación visual, animales, contaminación sonora, moralidad y contaminación atmosférica.

\section{Gráfico 8}

Tema en litigio. $N=\mathbf{2 5 4}$

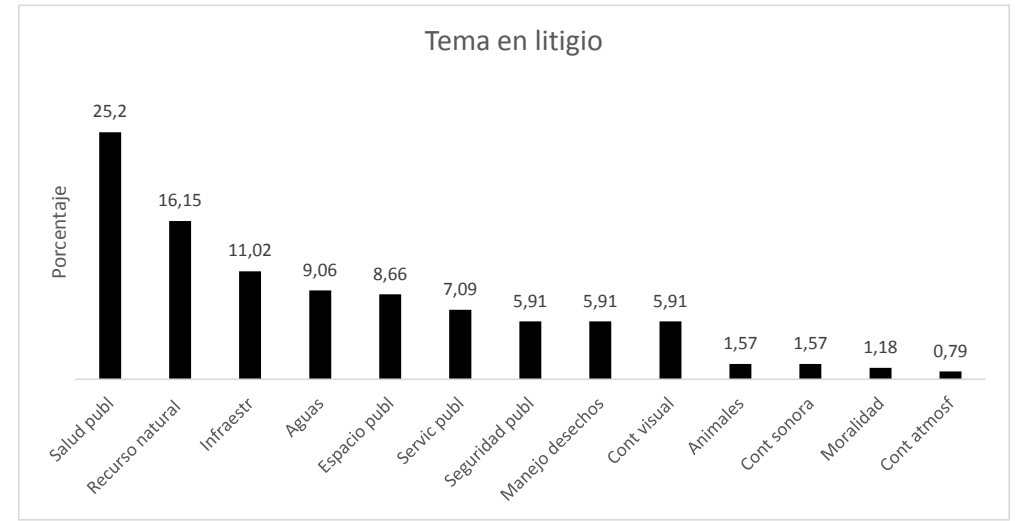

Fuente: elaboración propia

También analizamos los derechos colectivos que, de acuerdo con la demanda, se consideraron vulnerados en conexidad con el medio ambiente. Resulta llamativo que a pesar de que un $25 \%$ de los casos debatidos correspondía a una violación a la salud pública (gráfico 8, tema en litigio), solo en el 10\% de los casos este derecho colectivo se mencionó explícitamente en la demanda como uno de los derechos vulnerados ${ }^{39}$. El derecho colectivo más citado en estos casos fue la existencia del equilibrio ecológico ${ }^{40}(26 \%)$. Esta

39 Artículo 4, literal g de la Ley 472 de 1998.

40 Artículo 4, literal c de la Ley 472 de 1998. 
tendencia coincide con lo descrito en el gráfico 8, en la medida en que el $16 \%$ de los casos se relaciona con vulneraciones a un recurso natural (gráfico 9) ${ }^{41}$.

\section{Gráfico 9}

Otros derechos colectivos invocados. $N=254$

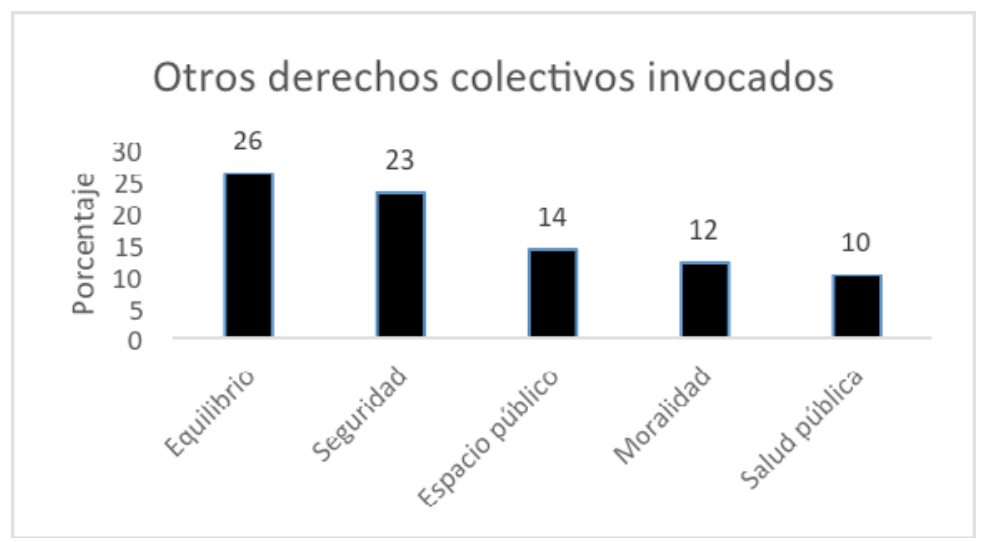

Fuente: elaboración propia

\section{G. Tasa de éxito de los demandantes}

El Consejo de Estado ha decidido la mayoría de los casos en favor de los demandantes (68\%, gráfico 10). En la gran mayoría de estos casos, el Consejo de Estado ordenó a la Administración implementar los correctivos necesarios para compensar el daño ambiental causado. Un ejemplo de esta tendencia es la acción popular AP198 de 2001, en la que la Junta de Acción Comunal del barrio Niza Sur demandó a la Alcaldía de Bogotá, a la Empresa de Acueducto de Bogotá, al Departamento Administrativo del Medio Ambiente (DAMA) y al Instituto Distrital de Recreación y Deporte (IDRD) por cuanto la construcción de un parque en la zona de preservación ambiental del humedal de Córdoba afectaba al humedal como hábi-

41 El gráfico 9 presenta los derechos colectivos más frecuentemente citados en conexidad con el medio ambiente. Además de los derechos colectivos recogidos en este gráfico, los demandantes citaron otros que por representar menos del 10\% de los casos no se incluyeron. Ejemplos de estos derechos son: desarrollo urbanístico de acuerdo a normas, acceso a servicios públicos y patrimonio público. 
tat para aves silvestres. El Consejo de Estado confirmó la sentencia del Tribunal y protegió el equilibrio ecológico y el aprovechamiento racional de los recursos naturales. Por eso, ordenó al Acueducto de Bogotá no dar inicio a la construcción en el humedal de Córdoba hasta obtener las licencias ambientales del caso ${ }^{42}$.

Al entender el comportamiento de los jueces en el litigio de acciones populares por medio ambiente, llama la atención que en su mayoría los demandantes son ciudadanos que demandan a gobiernos locales. En estos conflictos, el Consejo de Estado le concede razón a quien podría entenderse como la parte más débil, esto es, el ciudadano. Las acciones populares fueron diseñadas como un mecanismo que permitiera a los ciudadanos proteger sus intereses de violaciones ocasionadas por grandes actores como empresas, entidades prestadoras de servicios públicos domiciliarios y/o el Estado. En este escenario, las acciones populares por medio ambiente han alcanzado su objetivo.

Este hallazgo refuerza la literatura que ha explorado la capacidad de las partes involucradas en un litigio. Marc Galanter sostiene que hay actores en la sociedad que tienen la posibilidad de acceder a las cortes, mientras que otros actores sociales lo hacen de manera excepcional. Estos actores se comportan de manera muy diferente ante los estrados judiciales. Mientras los primeros (repeat players) tienen mayor experiencia y conocimiento del sistema judicial (y frecuentemente una mayor capacidad organizacional, técnica y financiera) los segundos (one-shooters) se enfrentan al sistema judicial de una manera muy diferente ${ }^{43}$.

En los casos a los que se refiere este análisis, los gobiernos locales pueden ser entendidos como repeat players que tienen a su disposición más experiencia, conocimiento y recursos para defenderse ante los estrados judiciales. Autores como Herbert M. Kritzer afirman que, al actuar ante estrados judiciales, el Estado cuenta con una posición de ventaja en la medida en que usualmente es un repeat

42 Colombia, Consejo de Estado, Radicación 25000-23-25-000-2000-0254-01(AP-198), 20 de septiembre de 2001, consejero ponente Jesús María Lemos-Bustamante.

43 Marc Galanter, Why the "Haves" Come out Ahead: Speculations on the Limits of Legal Change, 9 Law \& Society Review, 1, 95-160 (1974). Disponible en: http://jan.ucc.nau.edu/ phelps/Galanter\%20 1974.pdf 
player y que, además, el Estado crea las reglas de juego. Estas reglas tienden a favorecer al gobierno más que a los particulares ${ }^{44}$.

Por otro lado, los ciudadanos son frecuentemente "one-shooters" que tienen una menor capacidad que el Estado para enfrentar estos procesos. A pesar de lo anterior, este análisis evidencia que en las acciones populares medioambientales los ciudadanos tienden a ganar con mayor frecuencia que el Estado.

También vale la pena resaltar que esta tendencia es diferente si se analiza el litigio en acciones populares en las que se protegen otros derechos colectivos. En materia de moralidad administrativa, si bien la mayoría de demandantes son individuos, el Consejo de Estado falla a favor de las entidades estatales en la mayoría de los $\operatorname{casos}^{45}$. Es posible que esta variación en las tendencias se deba al tipo de prueba exigida en cada derecho colectivo. Como se puede observar en el gráfico 8, los casos de medio ambiente se relacionan con vulneraciones a la salud pública, recursos naturales e infraestructura, entre otros. En estos casos, el Consejo de Estado no requirió prueba cualificada de estas vulneraciones.

Por el contrario, en relación con los casos de violaciones a la moralidad administrativa el Consejo de Estado exigió de los demandantes una prueba que con frecuencia excedió la capacidad de las partes; por ejemplo, la prueba del ánimo de vulnerar la ley o los principios. De acuerdo con lo anterior, la tesis de la capacidad de las partes propuesta por Marc Galanter estaría confirmada en casos en los que el tipo de prueba es calificado y por tanto, las partes con mayores recursos estarán en mejor capacidad de allegarla o controvertirla. Ese no es el caso de las acciones populares medioambientales, en las que la mayoría de los demandantes — las partes débiles - obtiene decisiones favorables.

44 Herbert M. Kritzer, The Government Gorilla, Why Does Government Come Out Ahead in Appellate Courts?, en In Litigation: Do the "Haves" Still Come Out Ahead, 342-371 (Herbert M. Kritzer \& Susan S. Silbey, eds., Stanford Law and Politics, Stanford, California, 2003). Disponible en: http:// users.polisci.wisc.edu/kritzer/research/law_misc/gorilla.pdf

45 PÁez-Murcia, Ángela María; Estudio empírico: El litigio colectivo por moralidad administrativa en Colombia. (2017, en prensa) 


\section{Gráfica 10}

Decisión. $\mathbf{N}=\mathbf{2 5 4}$

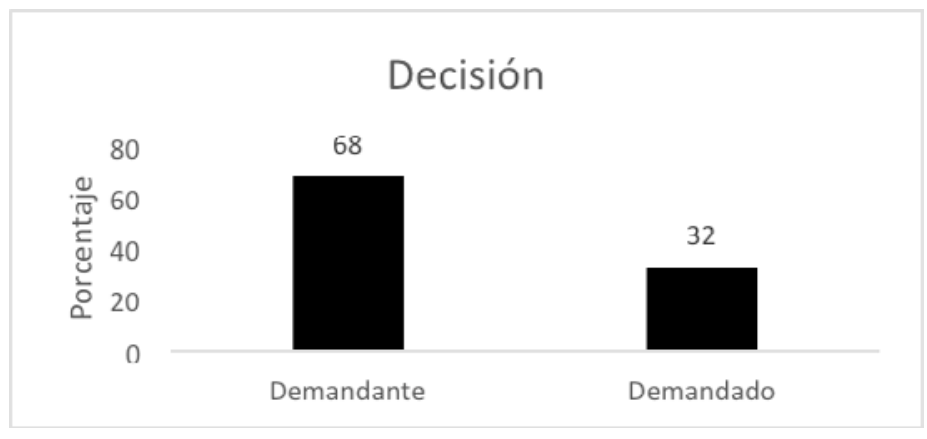

Fuente: elaboración propia

\section{H. Secciones de decisión y consejeros ponentes}

Los magistrados que más casos sustanciaron en el universo de casos analizados fueron Marco Antonio Velilla, Rafael Enrique Ostau de Lafont-Pianeta, María Claudia Rojas-Lasso, Camilo ArciniegasAndrade y Gabriel Eduardo Mendoza-Martelo (gráfico 11) ${ }^{46}$.

\section{Gráfico 11}

Porcentaje de decisiones proyectadas por magistrado

\begin{tabular}{|l|c|c|}
\hline \multicolumn{1}{|c|}{ Juez } & Porcentaje (\%) & Frecuencia \\
\hline Marco Antonio Velilla-Moreno & 16 & 39 \\
\hline Rafael Enrique Ostau de Lafont-Pianeta & 10 & 26 \\
\hline María Claudia Rojas-Lasso & 9 & 23 \\
\hline Camilo Arciniegas-Andrade & 8 & 20 \\
\hline Gabriel Eduardo Mendoza M. & 7 & 18 \\
\hline Otros magistrados & 50 & 127 \\
\hline Total & 100 & 253 \\
\hline
\end{tabular}

Fuente: elaboración propia

46 Cada uno de los magistrados ponentes restantes (33 magistrados) proyectaron menos del $5 \%$ de los casos analizados por lo que no se incluyen en esta tabla. 
Los magistrados que proyectaron un mayor número de decisiones fallaron a favor del demandante en la mayoría de los casos, en porcentajes que oscilan entre el 61 y el 87\% (gráfico 12. Tasa de éxito de los demandantes por magistrado ponente). Como se observa en el gráfico, la magistrada María Claudia Rojas proyectó el mayor porcentaje de decisiones a favor de los demandantes, mientras que el magistrado Gabriel Mendoza lo hizo en menor proporción.

\section{Gráfico 12 \\ Tasa de éxito de los demandantes por magistrado ponente}

\begin{tabular}{|c|c|}
\hline Juez & $\begin{array}{c}\text { Tasa éxito de los demandantes/ } \\
\text { magistrado ponente (\%) }\end{array}$ \\
\hline Marco Antonio Velilla-Moreno & 77 \\
\hline Rafael Enrique Ostau de Lafont-Pianeta & 73 \\
\hline María Claudia Rojas-Lasso & 87 \\
\hline Camilo Arciniegas-Andrade & 80 \\
\hline Gabriel Eduardo Mendoza M. & 61 \\
\hline
\end{tabular}

Fuente: elaboración propia

También comparamos la tasa de éxito de los demandantes en relación con la sección del Consejo de Estado que decidió el caso ${ }^{47}$. Específicamente, comparamos las decisiones tomadas por las secciones primera y tercera, ya que estas secciones decidieron el 79\% de los casos estudiados. La sección primera decidió el 62\% de los casos mientras que la sección tercera decidió el 17\%. Encontramos que mientras la sección primera falló a favor del demandante en $76 \%$ de los casos, la sección tercera lo hizo en 52\%. Así, la sección primera ha tendido a acceder a las pretensiones de los actores populares con más frecuencia que la sección tercera.

47 Conforme al Acuerdo 55, proferido por la Sala Plena del Consejo de Estado, la Sección Tercera es competente para conocer de las acciones populares que versen sobre asuntos contractuales y las relacionadas con el derecho colectivo a la moralidad administrativa. Todas las demás acciones populares son de conocimiento de la Sección Primera del Consejo de Estado. Colombia, Consejo de Estado, Sala Plena, Acuerdo 55, 5 de agosto de 2003. Disponible en: http://www.alcaldiabogota. gov.co/sisjur/normas/Norma1.jsp?i=17815 


\section{CONCLUSIONES}

Los datos analizados en este estudio demuestran que la supresión del incentivo económico en 2010 ha dejado a los actores populares sin posibilidades de compensación y, por tanto, en desequilibrio procesal con respecto a los demandados. La condena por costas no garantiza el equilibrio procesal ni ha suplido el vacío dejado por la eliminación del incentivo, ya que como lo muestra este estudio a los actores populares se les reconocen las costas procesales en un porcentaje bajísimo de casos.

Esto es especialmente preocupante ya que, como hemos demostrado, la gran mayoría de actores populares en temas ambientales son individuos, y no entidades estatales, organizaciones de la sociedad civil, fundaciones o empresas con recursos a su disposición. El posible impacto negativo de no contar con incentivos económicos es que un número cada vez más bajo de ciudadanos interpondrá acciones populares ambientales.

Este artículo también mostró que la eliminación del incentivo económico en 2010 no se basó en información o estudios que evidenciaran cómo el incentivo económico estaba motivando el litigio oportunista o temerario. Tampoco se promovió el fortalecimiento de las sanciones procesales que ya existían para los demandantes temerarios. Por el contrario, el gobierno, el Congreso y algunos comentaristas impulsaron esta importante reforma al procedimiento de las acciones populares con base en otras intuiciones, argumentos retóricos o intereses políticos y económicos "especiales".

A diferencia de lo que se sugirió en el contexto de la Ley 1425 de 2010, derogatoria del incentivo, el incentivo económico para las acciones populares no estaba generando una oleada de litigio temerario. Aunque en nuestra base de datos logramos identificar a algunos litigantes "recurrentes" (repeat players en términos de Galanter), no hay evidencia de que sus demandas fueran temerarias. Muy por el contrario, encontramos que estos litigantes no solo lograron visibilizar daños ambientales, sino que obtuvieron la protección por parte del Consejo de Estado de los derechos que invocaban como violados. Los accionantes recurrentes se especializaban en temas concretos como la ausencia de salas de necropsia en municipios, mejoramiento de las condiciones de salubridad en 
mataderos municipales, acceso de personas con movilidad reducida a puentes peatonales, y vallas publicitarias contaminantes, entre otros.

Adicionalmente, nuestra base de datos muestra de manera clara que en la mayoría de los casos el Consejo de Estado negaba el incentivo económico solicitado por el demandante, bien porque el accionante no hubiera probado una afectación al ambiente, o porque habiéndola demostrado, el caso había terminado con pacto de cumplimiento en vez de fallo judicial. Por otra parte, en los casos en los que el Consejo de Estado otorgaba el incentivo, lo hacía por montos muy bajos, lo cual desdibuja el argumento según el cual un número alto de litigantes se estaba enriqueciendo, gracias al incentivo económico otorgado por los jueces administrativos.

De este modo, la evidencia contenida en este artículo refuerza el argumento de los autores que han sostenido que en Colombia, tras la eliminación del incentivo económico, se ha producido un "desmonte" de las acciones populares. La evidencia más fuerte a este respecto es el descenso significativo del volumen de acciones populares interpuestas ante juzgados y tribunales administrativos tras la expedición de la Ley 1425 de 2010, documentado por órganos como el Consejo Superior de la Judicatura.

El argumento de algunos críticos del incentivo, según el cual este descenso en el número de acciones populares obedece a la desaparición de las acciones populares temerarias, no tiene fundamento empírico, según lo que arrojan los datos de este estudio. Esto ya que a partir de 2010 no se registra un cambio cualitativo en el litigio de acciones populares que permita identificar la desaparición del litigio oportunista, que según el universo de casos analizados no existió en los volúmenes señalados por los comentaristas críticos del incentivo. Más aún, este estudio encontró que el uso de las acciones populares descendió a partir de 2004, seis años antes de la eliminación del incentivo. Futuras investigaciones deberán explorar las causas de este descenso en el número de acciones instauradas para proteger el medio ambiente.

Con base en la evidencia existente puede decirse que desde 2010 los actores populares están más desprotegidos que nunca y tienen menos incentivos para defender el medio ambiente mediante el litigio de acciones populares. Este artículo mostró evidencia so- 
bre cómo los actores populares ambientales tienden a prevalecer sobre demandados con muchos más recursos a su disposición. El hecho de que en la mayoría de los casos el Consejo de Estado les dé la razón a individuos que buscan proteger el medio ambiente y la salud pública mediante acciones populares es, sin duda alguna, una amenaza para los intereses económicos y políticos de actores mucho más poderosos, quienes buscan obtener lucro económico independientemente del daño que pueden causar a ecosistemas protegidos y al bienestar de millones de ciudadanos vulnerables. 


\section{BIBLIOGRAFÍA}

\section{Libros}

Hensler, Deborah R.; Pace, Nick; Dombey-Moore, Bonnie; Giddens, Elizabeth; Gross, Jennifer \& Moller, Erik, Class Action Dilemmas: Pursuing Public Goals for Private Gain (Rand Corporation, Santa Mónica, California, 2000). Disponible en: http://www.rand.org/pubs/monograph_reports/MR969.html

\section{Colaboración en obras colectivas}

Kritzer, Herbert M., The Government Gorilla, Why Does Government Come Out Ahead in Appellate Courts?, en In Litigation: Do the "Haves" Still Come Out Ahead, 342371 (Herbert M. Kritzer \& Susan S. Silbey, eds., Stanford Law and Politics, Stanford, California, 2003). Disponible en: http://users.polisci.wisc.edu/kritzer/ research/law_misc/gorilla.pdf

\section{Revistas}

Galanter, Marc, Why the "Haves" Come out Ahead: Speculations on the Limits of Legal Change, 9 Law \& Society Review, 1, 95-160 (1974). Disponible en: http://jan.ucc. nau.edu/ phelps/Galanter\%201974.pdf

Hall, Mark A. \& Wright, Ronald F., Systematic Content Analysis of Judicial Opinions, 96 California Law Review, 1, 63-122 (2008). Disponible en: http://scholarship.law. berkeley.edu/cgi/viewcontent.cgi?article $=1186 \&$ context $=$ californialawreview

Hensler, Deborah R., The Future of Mass Litigation: Global Class Actions and ThirdParty Litigation Funding, 79 George Washington Law Review, 2, 306-323 (2011). Disponible en: http://www.gwlr.org/wp-content/uploads/2012/08/79-2-Hensler. pdf

Hensler, Deborah R., The Globalization of Class Actions: An Overview, 622 The Annals of the American Academy of Political and Social Science, 1, 7-29 (2009). Disponible en: https://www.researchgate.net/publication/249666853_The_Globalization_of_ Class_Actions_An_Overview

Lombard, Matthew; Snyder-Duch, Jennifer \& Campanella-Bracken, Cheryl, Content Analysis in Mass Communication: Assessment and Reporting of Intercoder Reliability, 28 Human Communication Research, 4, 587-604 (2002).

Londoño-Toro, Beatriz \& Torres-Villarreal, María Lucía, ¿Podrán las acciones populares colombianas sobrevivir a los recientes ataques legislativos y jurisprudenciales?, 124 Vniversitas, 235-259 (2012). Disponible en: http://revistas. javeriana.edu.co/index.php/vnijuri/article/view/14299/11509 


\section{Tratados internacionales}

Unión Internacional para la Conservación de la Naturaleza, International Union for Conservation of Nature, IUCN, Convención sobre Comercio Internacional de Especies Amenazadas de Fauna y Flora Silvestres, firmada en Washington el 3 de marzo de 1973. Disponible en: https://cites.org/esp/disc/text.php, http://www. alcaldiabogota.gov.co/sisjur/normas/Norma1.jsp?i=45530

\section{Normatividad colombiana}

Colombia, Consejo de Estado, Sala Plena, Acuerdo 55, 5 de agosto de 2003. Disponible en: http://www.alcaldiabogota.gov.co/sisjur/normas/Norma1.jsp?i=17815

Colombia, Consejo Superior de la Judicatura, Acuerdo PSAA06-3333 de 2006, por el cual se autorizan unos ajustes en el presupuesto de funcionamiento de la rama judicial, XIII Gaceta de la Judicatura, Extraordinaria No. 08, 2 de marzo de 2006. Disponible en: http://200.74.133.188/csj_portal/assets/EXTRA08-06.pdf

Colombia, Ley 393 de 1997, por la cual se desarrolla el artículo 87 de la Constitución Política, 43.096 Diario Oficial, 30 de julio de 1997. Disponible en: http://www. secretariasenado.gov.co/senado/basedoc/ley_0393_1997.html

Colombia, Ley 472 de 1998, por la cual se desarrolla el artículo 88 de la Constitución Política de Colombia en relación con el ejercicio de las acciones populares y de grupo y se dictan otras disposiciones, 43.357 Diario Oficial, 6 de agosto de 1998. Disponible en: http://www.secretariasenado.gov.co/senado/basedoc/ ley_0472_1998.html

Colombia, Ley 1425 de 2010, por medio de la cual se derogan artículos de la Ley 472 de 1998 Acciones Populares y Grupo, 47.937 Diario Oficial, 29 de diciembre de 2010. Disponible en: http://www.secretariasenado.gov.co/senado/basedoc/ ley_1425_2010.html

\section{Proyectos de ley colombianos}

Colombia, ponencia para primer debate al Proyecto de Ley 169 de 2010 Senado, 056 de 2009 Cámara, por medio de la cual se derogan algunos artículos de la Ley 472 de 1998 - Acciones Populares y de Grupo (Exposición de motivos Ley 1425/2010), 792/10 Gaceta del Congreso, 20 de octubre de 2010. Disponible en: http://www. imprenta.gov.co/gacetap/gaceta.nivel_3

Colombia, ponencia para segundo debate al Proyecto de Ley 169 de 2010 Senado, 056 de 2009 Cámara, por medio de la cual se derogan algunos artículos de la Ley 472 de 1998 - Acciones Populares y de Grupo (Exposición de motivos Ley 1425/2010), 885/10 Gaceta del Congreso, 11 de noviembre de 2010. Disponible en: http://www. imprenta.gov.co/gacetap/gaceta.nivel_3

Colombia, informe de conciliación al Proyecto de Ley 169 de 2010 Senado, 056 de 2009 Cámara, por medio de la cual se derogan algunos artículos de la Ley 472 de 1998 - Acciones Populares y de Grupo (Exposición de motivos Ley 1425/2010), 1082/10 Gaceta del Congreso, 13 de diciembre de 2010. Disponible en: http://www. 
imprenta.gov.co/gacetap/gaceta.nivel_3

Colombia, Texto definitivo aprobado en sesión plenaria al Proyecto de Ley 169 de 2010 Senado, 056 de 2009 Cámara, texto aprobado en sesión plenaria del Senado de la República del día 7 de diciembre de 2010 al Proyecto de Ley 169 de 2010 Senado, 056 de 2009 Cámara, por la cual se modifican algunos artículos de la Ley 472 de 1998 - Acciones Populares y de Grupo (Exposición de motivos Ley 1425/2010), 1118/10 Gaceta del Congreso, 22 de diciembre de 2010. Disponible en: http://www.imprenta.gov.co/gacetap/gaceta.nivel_3

\section{Jurisprudencia colombiana}

Colombia, Consejo de Estado, Radicación 25000-23-25-000-2000-0254-01(AP-198), 20 de septiembre de 2001, consejero ponente Jesús María Lemos-Bustamante.

Colombia, Consejo de Estado, Radicación 63001-23-31-000-2001-0293-01, 7 de diciembre de 2001, consejero ponente Darío Quiñones-Pinilla.

Colombia, Consejo de Estado, Radicación 63001-23-31-000-2001-0314-01, 7 de diciembre de 2001, consejero ponente Darío Quiñones-Pinilla.

Colombia, Consejo de Estado, Radicación 0001-23-31-000-2004-00972-01(AP), 4 de diciembre de 2008, consejero ponente Marco Antonio Velilla-Moreno.

Colombia, Consejo de Estado, Radicación 68001-23-15-000-20030052101, 22 de enero de 2009, consejero ponente Marco Antonio Velilla-Moreno.

Colombia, Corte Constitucional, Sentencia C-459-04, 11 de mayo de 2004, magistrado ponente Jaime Araújo-Rentería. Disponible en: http://www.corteconstitucional. gov.co/relatoria/2004/c-459-04.htm

Colombia, Corte Constitucional, Sentencia C-630-11, 24 de agosto de 2011, magistrada ponente María Victoria Calle-Correa. Disponible en: http://www. corteconstitucional.gov.co/relatoria/2011/c-630-11.htm

\section{Documentos, informes, reportes}

Corporación Excelencia en la Justicia, CEJ, Balance de los 10 años de las acciones populares y de grupo (Corporación Excelencia en la Justicia, CEJ, Bogotá, 2008). Disponible en: http://www.cej.org.co/index.php/component/docman/ doc_download/147-balance-de-los-10-anos-de-las-acciones-populares-y-degrupo?temid=59

Corporación Excelencia en la Justicia, CEJ, Eliminación del incentivo económico reduce las acciones populares (2014). Disponible en: http://www.cej.org.co/index.php/ justiciometros3/3897-eliminacion-del-incentivo-economico-reduce-las-accionespopulares 


\section{Medios de comunicación}

Bejarano, Ramiro, Los incentivos han muerto, Ámbito Jurídico (2012). Disponible en: https://www.ambitojuridico.com/BancoConocimiento/Educacion-y-Cultura/ noti-120229-07-los-incentivos-han-muerto.cshtml/

UPRIMNY, RodRigo, Las acciones populares ¿Impopulares en el Gobierno?, Semana (2 de septiembre de 2006). Disponible en: http://www.semana.com/opinion/articulo/ las-acciones-populares-impopulares-gobierno/80727-3

\section{Entrevistas}

Entrevista defensora delegada Camila, Defensoría del Pueblo, 30 de mayo de 2015, Bogotá, Colombia. Entrevistadora: Ángela M. Páez M.

Entrevista funcionario de nivel ejecutivo Procuraduría General de la Nación Carlos, 5 de mayo de 2014, Bogotá, Colombia. Entrevistadora: Ángela M. Páez M.

Entrevista servidor público Andrés, Bogotá, Distrito, 6 de julio de 2012, Bogotá Colombia. Entrevistadora: Ángela M. Páez M. 
